\title{
DETERMINAÇÃO DA ATIVIDADE ANTIMICROBIANA E AVALIAÇÃO DA TOXICIDADE DO Cereus jamacaru DC (MANDACARU) E DA Opuntia ficus-indica (L.) MILL (PALMA FORRAGEIRA)
}

Determination of antimicrobial activity and toxicity evaluation of Cereus jamacaru

DC (Mandacaru) and Opuntia ficus-indica (L.) Mill (Forage Palm)

Determinación da la actividad antimicrobiana y evaluación da la toxicidad Cereus

jamacaru dc (Mandacaru) y Opuntia ficus-indica (L) Mill. (Palma forrage)

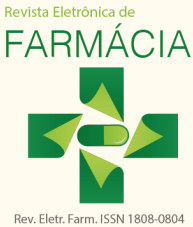

Paula Priscila Paixão Silva ${ }^{1 *}$, Meyrilane Lima', Thamara Silva', Arquimedes Melo',

Risonildo Cordeiro',

${ }^{1}$ Centro Universitário Tabosa de Almeida ASCES

*E-mail: paaulapriscila@hotmail.com

\section{RESUMO}

Introdução: A caatinga possui uma biodiversidade vegetal ímpar e entre suas inúmeras riquezas vegetais encontra-se o Cereus jamacaru e a Opuntia ficus-indica, que são cactos muito utilizados na medicina popular.

Objetivo: Objetivou-se determinar a atividade antimicrobiana e toxicológica a partir do extrato bruto seco destas cactáceas.

Metódos: A atividade antimicrobiana foi determinada por: Concentração Inibitória Mínima (CIM), Concentração Mínima Bactericida (CMB), Concentração Inibitória Mínima de Aderência (CIMA) e Potencial antibiótico. Para determinar a toxicidade foi utilizado o método de Meyer.

Resultados: No CIM e CMB o extrato de mandacaru foi efetivo frente a Proteus sp., Pseudomonas aeruginosa, Salmonella sp. e Staphylococcus aureus, bactéria esta que obteve os resultados mais expressivos nos testes. A palma foi efetiva frente Staphylococcus aureus e Pseudomonas aeruginosa, com halos de maior significado em sua maior concentração. No CIMA não houve formação de biofilme para Salmonella sp. e Proteus sp. na maior concentração de extrato do mandacaru. O potencial antibiótico foi de $37 \%$ comparado ao antibiótico padrão. O mandacaru obteve uma $\mathrm{CL}_{50}=19.591,1767 \mu \mathrm{g} / \mathrm{mL}$ e a palma de $16.645,5557 \mu \mathrm{g} / \mathrm{mL}$.

Conclusão: Ambas as plantas revelam ter um potencial antimicrobiano significativo, o que as tornam potenciais terapêuticos para o desenvolvimento de novos fitoterápicos, visto que as mesmas revelaram-se praticamente atóxicas nas condições testadas.

Palavras-chave: Cactaceae. Microbiologia. Testes de Toxicidade.

\section{ABSTRACT}

Introduction: The scrub has a unique vegetative biodiversity and among its many vegetables wealth is the Cereus jamacaru and Opuntia ficus-indica, cactus widely used in folk medicine.

Objective: This study aimed to determine the antimicrobial and toxicological activity from the dry crude extract of these cactuses.

Methods: Antimicrobial activity was determined by: Minimum Inhibitory Concentration (MIC), Minimum Bactericidal Concentration (CMB), Minimum Inhibitory Concentration of Adherence (CIMA) and antibiotic potential. To determine toxicity was used Meyer method.

Results: The WCC and the CMB mandacaru extract were effective against Proteus spp., Pseudomonas aeruginosa, Salmonella $\mathrm{sp}$. and Staphylococcus aureus bacteria this, which obtained the most significant test results. The palm was effective front Staphylococcus aureus and Pseudomonas aeruginose with halos of greater meaning in its highest concentration. In UP there was 
no biofilm formation in Salmonella sp. and Proteus sp. the highest concentration of mandacaru extract. The antibiotic potential was 37\% compared to standard antibiotic. The mandacaru obtained a LC50 = 19591.1767 / mL and palm $16645.5557 / \mathrm{mL}$.

Conclusion: Both plants have revealed a significant antimicrobial potential, making them potential therapeutic for the development of new herbal seen that the same proved to be practically non-toxic in the tested conditions.

Keywords: Cactaceae. Microbiology. Toxicity Tests.

\section{RESUMEN}

Introducción: La caatinga tiene una biodiversidad vegetal única y entre sus muchas riquezas vegetales encontramos el Cereus jamacaru y la Opuntia ficus-indica, que son cactus ampliamente utilizados en la medicina popular.

Objetivo: Este estudio tuvo como objetivo determinar la actividad antimicrobiana y toxicológicadel extracto crudo seco de esos cactus. Métodos: La actividad antimicrobiana fue determinada por: concentración inhibitoria mínima (MIC), Concentración mínima bactericida (CMB), Concentración inhibitoria mínima de Adhesión (CIMA) y p Potencial antibiótico. Para determinar la toxicidad se utilizó el método de Meyer.

Resultados: El CMI y el extracto CMB Mandacaru hacen efectivas frente a Proteus spp., Pseudomonas aeruginosa, Salmonella sp. y esta bacteria Staphylococcus aureus, que obtuvieron los resultados más significativos. La palma estaba delante efectiva Staphylococcus aureus y Pseudomonas aeruginosa con halos de mayor significado en su concentración más alta. En UP no hubo formación de biopelículas de Salmonella sp. y Proteus sp. la mayor concentración de extracto de Mandacaru. El potencial antibiótico fue del 37\% en comparación con el antibiótico estándar. El Mandacaru obtuvo una $\mathrm{CL}_{50}=19591.1767 / \mathrm{ml}$ y la palma $16645.5557 / \mathrm{ml}$.

Conclusión: Ambas plantas han revelado una tener un potencial antimicrobiano significativo, lo que les proporciona un enorme potencial terapéutico para el desarrollo de nuevos medicamentos fitoterápicos, pues esos cactus se revelan prácticamente atóxicos en las condiciones testados.

Palabras clave: Cactaceae. Microbiología. Pruebas de Toxicidad.

\section{INTRODUÇÃO}

Com o surgimento de novos antimicrobianos houve de forma paralela o aparecimento de resistência aos mesmos, diminuindo assim a efetividade desses fármacos, refletindo em pacientes infectados sem opções de tratamento devido à presença de microrganismos multirresistentes, tornando a resistência bacteriana um problema mundial de saúde pública e atraindo a atenção de órgãos nacionais e internacionais de saúde ${ }^{(1)}$.

Diante desta realidade, a necessidade de novas substâncias antimicrobianas a partir de fontes naturais, incluindo plantas, tem ganho importância nas companhias farmacêuticas, pois além de bastante utilizadas, as plantas medicinais são uma crescente fonte de estudos ${ }^{(2,3)}$.

A utilização de plantas medicinais pelo homem é relatada desde a pré-história. O seu uso popular é o que muitas comunidades têm como alternativa viável para o tratamento de doenças ou manutenção da saúde, visto que em sua grande maioria este é o único recurso disponível para o tratamento de doenças na região. Uma forma de terapia medicinal que vem crescendo notadamente nestes últimos anos movimentando anualmente bilhões de dólares é a fitoterapia. O Brasil pode ser considerado um país privilegiado, visto que apresenta uma rica biodiversidade. E é no Brasil, mais especificamente na Região Nordeste, que encontramos um bioma exclusivo: a caatinga ${ }^{(4,5,6,7,8)}$. 
Região que encaixa-se perfeitamente neste contexto, entretanto, embora trate-se de um bioma exclusivamente brasileiro, com uma biodiversidade vegetal ímpar, ainda é pouco conhecido e explorado. A Caatinga ocupa $11 \%$ do território nacional, e merece sem dúvida um enfoque apropriado e políticas públicas feitas exclusivamente para a área que engloba ${ }^{(9)}$.

Dentre as riquezas emergidas neste bioma está a Cereus jamacaru DC., uma cactácea típica dessa região do Brasil, conhecida popularmente como mandacaru; e a Opuntia ficus-indica L., conhecida popularmente como palma forrageira e/ou palma doce. Ambas cactáceas são bastante utilizadas na alimentação de bovinos nos longos períodos de seca que ocorrem na região devido ao seu enorme teor água; e na medicina popular, principalmente como antibiótico, diurético, analgésico e anti-inflamatório, para tratar problemas intestinais, tosses, afecções cardíacas e nervosas, dor de dente, curar alguns tipos de úlceras e para tentar o controle de diabetes e colesterol, ações estas que são justificadas pela sua diversidade de metabólitos $(10,11,12,13,14,15)$

Os principais componentes químicos identificados em Cereus jamacaru DC são duas aminas (tiramina e N-metiltiramina), além da presença da hordenina e tirosina. A tiramina é conhecida por sua atividade simpatomimética e provável atividade cardiotônica. Enquanto a Opuntia ficus-indica L., caracteriza-se por seu alto teor de água, minerais, carboidratos solúveis, vitaminas, e elevada digestibilidade. Nos seus cladódios verifica-se a presença de flavonoides, taninos, saponinas antraquinonas e a relevante frequência da ß-sitosterol. Diversidade de metabólitos esta, que justifica seu uso como anti-inflamatório(12,15,16).

De acordo com estudos realizados, o Cereus jamacaru DC demonstrou potencial antibacteriano sobre o crescimento dos seguintes microrganismos: Streptococcus epidermidis, Staphylococcus aureus, Pseudomonas aeruginosa e Escherichia coli. Testes realizados in vitro demonstram que o extrato etanólico da palma forrageira possui uma boa atividade antibacteriana frente a Micrococcus, S. aureus, Klebsiella. pneumoniae, Salmonella typhi e E. coli. Além de uma significativa atividade antifúngica(12,15).

Apesar do grande potencial terapêutico tanto do mandacaru quanto da palma, não podemos esquecer do potencial tóxico que estas plantas podem apresentar. Neste caso especificamente pressupõe-se que a toxicidade seja baixa devido a utilização das mesmas como fonte de alimentação para animais, entretanto, há necessidade de se conhecer seus aspectos tóxicos ${ }^{(17)}$. Diante deste contexto, o presente estudo tem por objetivo determinar a atividade antimicrobiana e o potencial antibiótico dos extratos brutos secos do Cereus jamacaru DC e da Opuntia ficus-indica L. na busca por uma alternativa ao combate da resistência bacteriana, além de realizar uma avaliação da toxicidade $\left(\mathrm{CL}_{50}\right)$ dos mesmos.

\section{METODOLOGIA}

\section{Material Vegetal}

Foram utilizadas partes aéreas do Cereus jamacaru DC. (Mandacaru) e da Opuntia ficus-indica L. (Palma). Os materiais vegetais necessários foram coletados na zona rural do município de Belo Jardim - PE, Brasil, e na zona rural do município de Caruaru - PE, Brasil. Ambos os materiais botânicos foram identificados pela Profa . Dra . Rita de Cássia Araújo Pereira (curadora do Herbário - IPA) e a exsicata incorporada ao mesmo herbário com os respectivos números: Mandacaru 90637 e Palma 90637.

\section{Cepas Utilizadas}

A ação antibacteriana do Cereus jamacaru DC. e da Opuntia ficus-indica L. foi testada frente às cepas de Staphylococcus aureus, Escherichia coli, Pseudomonas aeruginosa, Klebsiella pneunoniae, Candida albicans, Salmonella sp. e Proteus sp.

\section{Preparação do extrato vegetal}

Para a obtenção do extrato bruto seco de Cereus jamacaru DC. e de Opuntia ficus-indica L., foram coletadas as partes aéreas das plantas. Logo após a coleta, as partes foram lavadas e secadas com papel absorvente, após esse procedimento, as 
amostras foram maceradas em balão de fundo chato e adicionado a totalidade das drogas vegetais, separadamente, e vetado sobre ela solução extrativa alcoólica, essa ficou em repouso durante sete dias. Após o período de repouso, realizou-se extrusão e os extratos foram filtrados em papel filtro, o produto foi o extrato bruto fluido, que foi acondicionado em vidro âmbar. Em seguida esses extratos foram levados ao rotaevaporador a uma temperatura de $45^{\circ} \mathrm{C}$, para a evaporação do solvente. Por fim, logo após a rotaevaporação, os extratos foram levados para o dessecador, obtendo-se assim o extrato alcoólico bruto seco do Cereus jamacaru DC. e outro da Opuntia ficus-indica L.

\section{Determinação da Concentração Inibitória Mínima (CIM) e da Concentração Mínima Bactericida (CMB)}

A determinação da Concentração Inibitória Mínima (CIM) e da Concentração Mínima Bactericida (CMB) dos extratos do Cereus jamacaru DC. e da Opuntia ficus-indica L. frente a bactérias patógenas, foram realizadas a partir da técnica de poços. Foram preparados inóculos das respectivas bactérias em solução salina, a partir de semeios por esgotamento; para controlar a concentração bacteriana foi utilizada a escala 0,5 de McFarland. Com o auxílio do swab, foram semeadas com o inóculo toda a extensão das placas de Petri contendo ágar Mueller-Hinton. Em cada placa semeada foram confeccionados quatro poços de 6 $\mathrm{mm}$ de diâmetro, para a inserção de $50 \mu \mathrm{L}$ de extrato bruto seco em diferentes concentrações, partindo de $100 \%$ seguido pelas diluições 50\%, 25\% e 12,50\% do extrato bruto seco do Cereus jamacaru DC. e da Opuntia ficus-indica L. Após essa etapa, as placas foram incubadas a $37^{\circ} \mathrm{C}$ por 24 horas, para posterior mensuração dos halos em milímetros $(\mathrm{mm})$ e determinação da Concentração Inibitória Mínima (CIM), sendo esta entendida como a menor concentração do extrato capaz de inibir o crescimento bacteriano, e determinação da Concentração Mínima Bactericida (CMB), entendida como a maior concentração do extrato capaz de inibir o crescimento bacteriano com maior expressividade ${ }^{(26)}$.

\section{Determinação da Concentração Inibitória Mínima de Aderência (CIMA)}

A Concentração Inibitória Mínima de Aderência (CIMA) foi determinada na presença de sacarose a 5\%, usando as concentrações $100 \%, 50 \%, 25 \%, 12,5 \%$. As cepas serão subcultivadas a $37^{\circ} \mathrm{C}$ em caldo Mueller-Hinton em microaerofilia, por um período de 24 horas obtendo-se um inóculo de $10^{6} \mathrm{UFC} / \mathrm{mL}$, equivalente a $20 \mu \mathrm{L}$ de suspensão bacteriana, com os tubos inclinados a $30^{\circ} \mathrm{C}$. A leitura foi realizada através da observação visual da aderência da bactéria às paredes do tubo, após coloração com azul de metileno. A CIMA é definida como a menor concentração do agente antibacteriano em meio com sacarose, que impediu a aderência ao tubo de vidro ${ }^{(26)}$.

\section{Determinação do Potencial Antibiótico}

O método analítico biológico empregado para a determinação da potência antibiótica dos extratos brutos secos do Cereus jamacaru DC. e da Opuntia ficus-indica L. foi a difusão em ágar Mueller-Hinton em placas com aplicação de diferentes concentrações dos extratos e do antimicrobiano padrão (amoxicilina). Preparou-se uma solução padrão com 0,50 g de amoxicilina diluída em soro fisiológico. Para a preparação dos inóculos, a princípio faz-se suspensões bacterianas, comparando a turbidez com o padrão 0,5 da escala de McFarland. Para as amostras do extrato bruto alcoólico, foram preparadas soluções em soro fisiológico nas concentrações de 100\%, 50\%, 25\% e 12,50\% dos extratos brutos secos. Sendo estas pipetadas na quantidade de $100 \mu \mathrm{l}$ para os cilindros previamente preparados sob as placas de Petri com os microrganismos padrões. Posteriormente foram levadas à incubação por 18 horas em estufa a $37^{\circ} \mathrm{C}$. Os resultados serão lidos na forma de halos de inibição e tabelados.

\section{Determinação da Concentração Letal Média $\left(\mathrm{CL}_{50}\right)$}

A determinação da $\mathrm{CL}_{50}$ seguiu o padrão descrito por Meyer, 1982 ${ }^{(27)}$. Os ovos de Artemia salina Leach foram incubados em solução salina em um recipiente de vidro, o qual é mantido sob iluminação artificial (lâmpada de 40 W), em temperatura 
constante de $28^{\circ} \mathrm{C}$, por um período de 48 horas. Após este procedimento, obtém-se o estágio de metanáuplio, modelo padrão para testes de toxicidade devido a sua maior sensibilidade.

Foram utilizados $50 \mathrm{mg}$ do extrato bruto, nos quais foram adicionados $1 \mathrm{~mL}$ de Tween 80 a $5 \%$ para ajudar a solubilização do mesmo. As soluções foram homogeneizadas e o volume completado para $5 \mathrm{~mL} c o m$ água salinizada a $\mathrm{pH}=8,0$. Destas soluções foram retiradas alíquotas de 500, 375, 250, 125, 50 e $25 \mu \mathrm{L}$ que foram transferidas para tubos de ensaio que já continham $5 \mathrm{~mL}$ de solução salina, obtendo-se concentrações de 1000, 750, 500, 250, 100 e $50 \mu \mathrm{g} / \mathrm{mL}$ para cada extrato. $\mathrm{O}$ teste foi feito em triplicata. As amostras foram submetidas à iluminação artificial durante 24 horas. Após esse período, foi realizada a contagem do número de larvas vivas e mortas e os dados tabulados utilizando o programa Microcal Origin 4.1.

\section{RESULTADOS E DISCUSSÃO}

Ambos os extratos bruto seco de cor esverdeada, consistência viscosa e odor característico apresentaram boa atividade antibacteriana. O Cereus jamacaru DC. apresentou halos de CIM de $9 \mathrm{~mm}$ para Staphylococcus aureus na concentração 12,5\%; 13 mm frente a Pseudomonas aeruginosa e Salmonella sp. ambas na concentração 25\%; e 14 mm para Proteus sp. na concentração 50\%; formou halos de Concentração Mínima Bactericida (CBM) de $21 \mathrm{~mm}$ para Staphylococcus aureus; $18 \mathrm{~mm}$ Pseudomonas aeruginosa; $19 \mathrm{~mm}$ Salmonella sp.; e $16 \mathrm{~mm}$ para Proteus sp. ambos na concentração 100\%.

A Opuntia ficus-indica L. apresentou halos indicativos de uma Concentração Inibitória Mínima (CIM) de 18 mm para Staphylococcus aureus na concentração 12,5\% e $13 \mathrm{~mm}$ para Pseudomonas aeruginosa na concentração 50\%. Os halos obtidos na Concentração Mínima Bactericida (CBM) foram de $25 \mathrm{~mm}$ frente a Staphylococcus aureus e de $17 \mathrm{~mm}$ frente a Pseudomonas aeruginosa, ambos na concentração 100\%. Tanto o Cereus jamacaru DC. como a Opuntia ficus-indica L. apresentaram uma atividade antimicrobiana mais significativa frente a Staphylococcus aureus, visto que houve formação de halos de maior expressividade em todas as concentrações.

Tabela 1. Concentração Mínima Inibitória e Bactericida (CIM e CBM) do Cereus jamacaru DC. e da Opuntia ficus-indica L. expressa em milímetros frente a microrganismos patógenos

\begin{tabular}{|c|c|c|c|c|c|c|c|c|}
\hline \multirow[b]{2}{*}{ Microrganismos Testados } & \multicolumn{4}{|c|}{ Mandacaru } & \multicolumn{4}{|c|}{ Palma } \\
\hline & $100 \%$ & $50 \%$ & $25 \%$ & $12,5 \%$ & $100 \%$ & $50 \%$ & $25 \%$ & $12,5 \%$ \\
\hline Staphylococcus aureus & $21 \mathrm{~mm}$ & $19 \mathrm{~mm}$ & $17 \mathrm{~mm}$ & $9 \mathrm{~mm}$ & $25 \mathrm{~mm}$ & $22 \mathrm{~mm}$ & $20 \mathrm{~mm}$ & $18 \mathrm{~mm}$ \\
\hline Pseudomonas aeruginosa & $18 \mathrm{~mm}$ & $16 \mathrm{~mm}$ & $13 \mathrm{~mm}$ & - & $17 \mathrm{~mm}$ & $13 \mathrm{~mm}$ & - & - \\
\hline Salmonella & $19 \mathrm{~mm}$ & $16 \mathrm{~mm}$ & $13 \mathrm{~mm}$ & - & - & - & - & - \\
\hline Proteus & $16 \mathrm{~mm}$ & $14 \mathrm{~mm}$ & - & - & - & - & - & - \\
\hline Klebsiella pneunoniae & - & - & - & - & - & - & - & - \\
\hline Escherichia coli & - & - & - & - & - & - & - & - \\
\hline Candida albicans & - & - & - & - & - & - & - & - \\
\hline
\end{tabular}

Fonte: Elaborada pelos autores, 2016. 
Os resultados correspondentes ao Cereus jamacaru DC. quanto a Concentração Inibitória Mínima (CIM) e Concentração Mínima Bactericida (CBM) são semelhantes aos encontrados em estudos anteriores que mostram que o mandacaru apresenta atividade frente Staphylococcus aureus, Pseudomonas aeruginosa e Escherichia coli(12). No presente estudo, a Escherichia coli foi a única dentre as três cepas citadas que não foi sensível ao extrato do Cereus jamacaru DC., entretanto, variações referentes à determinação da CIM e CBM de extratos de plantas podem ter interferência de vários fatores. Dentre eles estão a técnica aplicada, o microrganismo e a cepa utilizada no teste, a origem da planta, a época da coleta, modo e tipo de extrato(21).

Quanto a Opuntia ficus-indica L., resultados diferentes do presente estudo foram encontrados por Necchi(13) ${ }^{(12 m}$ outra espécie de palma forrageira, a Nopalea cochenillifera L. Além da atividade frente a Staphylococcus aureus demonstrada também pela espécie Opuntia ficus-indica L., o estudo demonstra atividade frente aos microrganismos Klebsiella pneumoniai, Candida albicans e Escherichia coli, atividades estas que não foram evidenciadas nesta pesquisa; entretanto, tanto a região de coleta do material vegetal quanto o tipo de extrato diferem entre si. Necchi(13) utilizou o extrato etanólico para extrusão da palma forrageira coletada no Rio Grande do Sul, Brasil, região que difere do modo de cultivo da região Nordeste, onde a Opuntia ficusindica L. foi coletada, e a composição química da palma forrageira varia segundo seu cultivo, idade do cladódio e espécie(11).

Em relação à concentração inibitória mínima de aderência (CIMA), apenas o extrato do Cereus jamacaru DC. impediu a formação de biofilme frente algumas das cepas em testes. Positivou contra as bactérias Salmonella sp. e Proteus sp. na concentração 100\%. Para as demais concentrações e bactérias o resultado foi negativo para antiaderência, ou seja, houve formação de biofilme.

Tabela 2. Perfil de atividade antiaderente do Cereus jamacaru DC. e da Opuntia ficus-indica L.

\begin{tabular}{|c|c|c|c|c|c|c|c|c|}
\hline \multirow[b]{2}{*}{$\begin{array}{c}\text { Microrganismos } \\
\text { Testados }\end{array}$} & \multicolumn{4}{|c|}{ Mandacaru } & \multicolumn{4}{|c|}{ Palma } \\
\hline & $100 \%$ & $50 \%$ & $25 \%$ & $12,5 \%$ & $100 \%$ & $50 \%$ & $25 \%$ & $12,5 \%$ \\
\hline $\begin{array}{c}\text { Staphylococcus } \\
\text { aureus }\end{array}$ & Negativo & Negativo & Negativo & Negativo & Negativo & Negativo & Negativo & Negativo \\
\hline $\begin{array}{c}\text { Pseudomonas } \\
\text { aeruginosa }\end{array}$ & Negativo & Negativo & Negativo & Negativo & Negativo & Negativo & Negativo & Negativo \\
\hline Salmonella sp. & Positivo & Negativo & Negativo & Negativo & - & - & - & - \\
\hline Proteus sp. & Positivo & Negativo & Negativo & Negativo & - & - & - & - \\
\hline
\end{tabular}

Fonte: Elaborada pelos autores, 2016.

A estrutura altamente organizada dos biofilmes, comunidades de microrganismos estruturados dentro de uma matriz de exopolissacáridos (EPS) com função de proteger os microrganismos em ambientes de stress, tende a ser mais resistente à terapia antimicrobiana em comparação com as células planctônicas livres devido à difusão lenta do antimicrobiano nas camadas interiores do biofilme ${ }^{(18,19)}$. O presente estudo condiz com ambos estudos ${ }^{(18,19)}$ quando demostra que o extrato da Opuntia ficusindica L. negativou ao teste realizado, sendo apenas efetivo frente às células livres, enquanto o extrato do Cereus jamacaru DC. positivou frente apenas duas bactérias na sua maior concentração, tendo o mesmo sensibilizado um número superior de cepas livres.

Metabólitos como flavonoides e taninos presentes nesses cactos estão sendo propostos como alternativa para conter a resistência bacteriana. Mais de 70\% das bactérias patogênicas são resistentes a pelo menos um antibiótico de uso clínico, dentre 
estas destaca-se a Staphylococcus aureus, responsável por diversos casos de infecções ${ }^{(9)}$. Esta bactéria detém os resultados mais expressivos dentre as cepas testadas em ambos os extratos, com halos de inibição de $21 \mathrm{~mm}$ na concentração 100\%, $19 \mathrm{~mm}$ na concentração 50\%, 17 mm na concentração $25 \%$ e 9 mm na concentração 12,5\% para o extrato do Cereus jamacaru DC. O extrato da Opuntia ficus-indica L. formou halos de $25 \mathrm{~mm}$ na concentração 100\%, 22 mm em 50\%, 20 mm em 25\% e 18 mm na menor concentração de $12.5 \%$.

Observa-se no Gráfico 1 que o extrato bruto seco de Mandacaru comparado ao antibiótico padrão (Amoxicilina) tem uma atividade de $37 \%$ em relação à atividade da amoxicilina frente ao microrganismo Staphylococcus aureus.

A palma forrageira obteve um resultado ainda mais expressivo, sua atividade frente o Staphylococcus aureus quando comparado a atividade da amoxicilina foi de $46 \%$ ou seja, a potência do produto é $46 \%$ da atividade do antibiótico padrão.

Gráfico 1. Efetividade dos extratos frente a cepa Staphylococcus aureus em relação ao antibiótico padrão

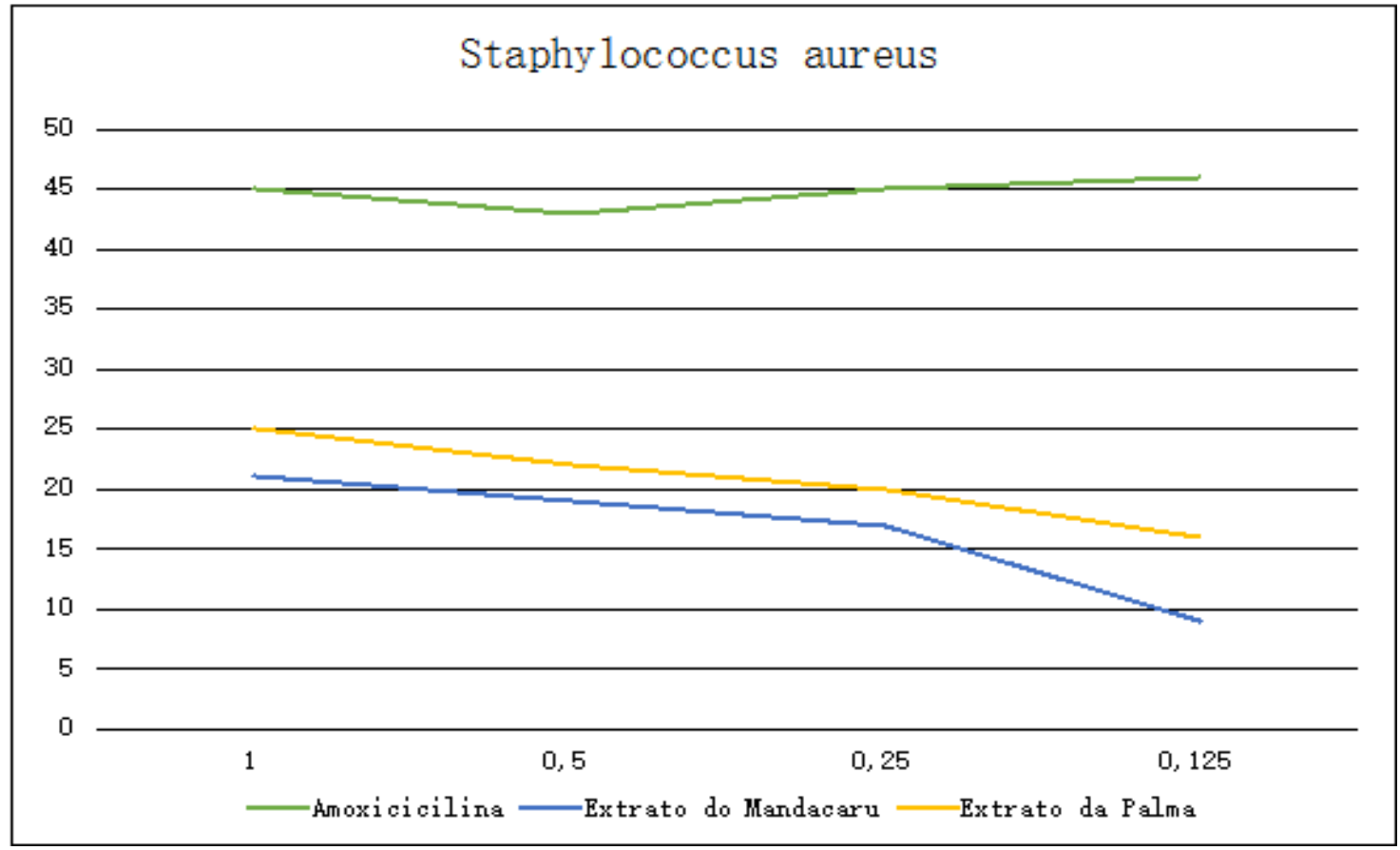

Fonte: Elaborada pelos autores, 2016.

Quanto à determinação da toxicidade, a contagem de Artemia salina Leach vivas e mortas foi tabulada no Programa Microcal Origin 4.1. Obteve-se os valores das variáveis $\mathrm{A}$ e $\mathrm{B}$, a partir dos quais se calculou a $\mathrm{CL}_{50}$ e disponibilizou-se no gráfico, Concentração Letal Média $\left(\mathrm{CL}_{50}\right)$ do mandacaru e da palma com os eixos \% de vivos X Concentração $(\mu \mathrm{g} / \mathrm{mL})$.

Não houve um relevante número de mortes em nenhuma das concentrações testadas tanto do mandacaru, que obteve uma $\mathrm{CL}_{50}=19.591,1767 \mu \mathrm{g} / \mathrm{mL}$., quanto da palma, que obteve uma $\mathrm{CL}_{50}=16.645,6667 \mu \mathrm{g} / \mathrm{mL}$. Ambos extratos, segundo 
Bussman ${ }^{(22)}$, são praticamente atóxicos nas concentrações e condições testadas, visto que obtiveram resultados bem acima de 1000 e o mesmo considera uma $\mathrm{CL}_{50}$ acima de $1000 \mu \mathrm{g} / \mathrm{mL}$ como praticamente atóxica.

Gráfico 2. Número de larvas vivas pela concentração de extrato do Cereus jamacaru DC. (Mandacaru) e da Opuntia ficus-indica L. (Palma) resultantes do teste de Artemia salina

Mandacaru

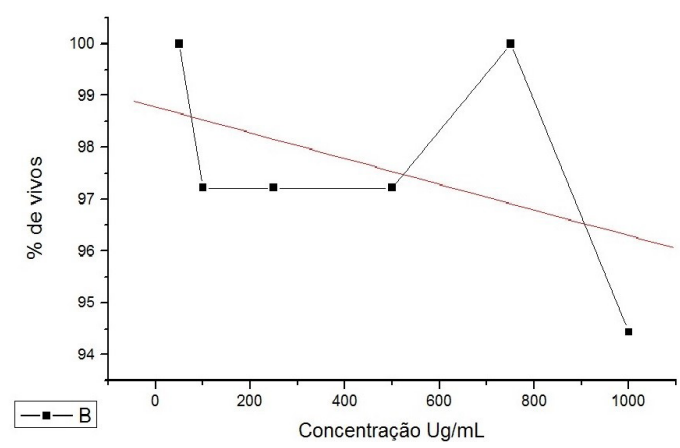

Palma

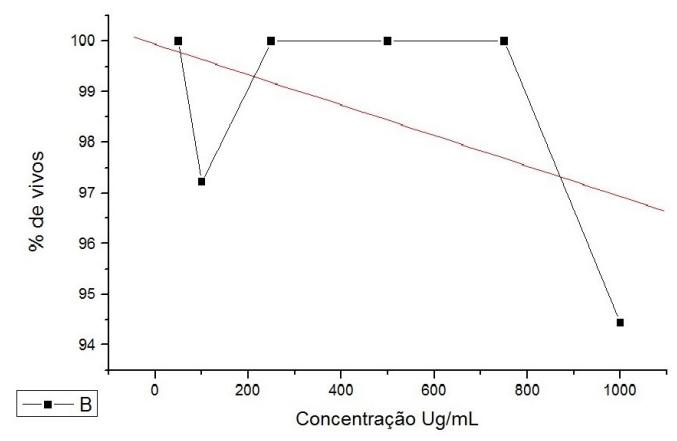

Fonte: Elaborada pelos autores, 2016

O fato de ambas cactáceas serem consideradas praticamente atóxicas justifica o consumo das mesmas como fonte de alimento para fauna silvestre e de principalmente nos períodos de seca serem largamente utilizadas pelos agricultores para alimentação de bovinos ${ }^{(23,24)}$.

Segundo Messias et al. 2010(16), em seu estudo de toxicidade aguda, foi verificado que o extrato bruto de C. jamacaru não apresentou ação cumulativa; em doses menores produziu efeito estimulante no Sistema Nervoso Central (SNC), enquanto doses mais elevadas apresentaram efeitos depressores, porém são necessários estudos farmacológicos mais aprofundados para avaliar a potencialidade desse vegetal.

\section{CONCLUSÃo}

Os resultados apresentados pelas cactáceas foram bastante relevantes. Ambas mostraram-se efetivas frente cepas que estão em grande evidência na resistência bacteriana. Apresentaram um potencial antibiótico significativo de $47 \%$ comparado ao antibiótico padrão (amoxicilina), e na Artemia salina Leach obtiveram uma curva de interpretação considerada praticamente atóxica.

Diante desses resultados podemos concluir que tanto o Cereus jamacaru DC. como a Opuntia ficus-indica L. são plantas com um potencial terapêutico significativo, contribuindo no desenvolvimento de novos protótipos de produtos naturais para o desenvolvimento de novos medicamentos fitoterápicos. 


\section{REFERÊNCIAS}

1. Álvares CA. Resistencia bacteriana, transmisión cruzada y control de la infección asociada a la atención en salud. Infect. [online]. 2010, vol.14, n.2 [cited 2012-08-23], pp. 91-92.

2. Duarte MCT. Atividade antimicrobiana de plantas medicinais e aromáticas utilizadas no Brasil. Construindo a História dos Produtos Naturais \#7, outubro de 2006.

3. Wannmacher L. Uso indiscriminado de antibióticos e resistência microbiana: Uma guerra perdida? ISSN 1810-0791. 1(4): Brasília, Março de 2004.

4. Gomes ECS, Barbosa J, Vilar FCR, Perez JO, Ramalho RC. Plantas da caatinga de uso terapêutico: Levantamento etnobotânico. Il Congresso de Pesquisa e Inovação da Rede Norte Nordeste de Educação Tecnológica, 2. 158. João Pessoa. Brasil. 2007.

5. Roque AA, Rocha RM, Loiola MIB. Uso e diversidade de plantas medicinais da Caatinga na comunidade rural de Laginhas, município de Caicó, Rio Grande do Norte (nordeste do Brasil). Rev. Bras. Pl. Med. 12(1): 31-42, 2010.3.

6. Albuquerque UP, Medeiros PM, Almeida ALS, Monteiro JM, Lins EMF, Melo JG, Santos JPS. Medicinal plants of the caatinga (semi-arid) vegetation of NE Brazil: A quantitative approach. Journal of Ethnopharmacology. 114 (1): 325-354, 2007.

7. Yunes RA, Pedrosa RC, Cechinel V. Fármacos e fitoterápicos: A necessidade do desenvolvimento da indústria de fitoterápicos e fitofármacos no Brasil. Quim. Nova. 24(1): 147-152, 2001.

8. Hoeffel JLM, Gonçalves NM, Fadini AAB, Seixas SRC. Conhecimento tradicional e uso de plantas medicinais nas apas's Cantareira/SP e Fernão dias/MG. Revista VITAS. 2(1): 05-09, 2011

9. Magalhões T. Revista do instituto humanitasunisinos, nº 389 -AnoXII -23/04/2012 - ISSN 1981-8769.

10. Cavalcanti NB \& Resende GM. Efeito de diferentes substratos no desenvolvimento de mandacaru (Cereus jamacaru P.DC.), facheiro (Pilosocereus pachycladus RITTER), xiquexique (Pilosocereus gounellei (A. WEBWR EX K. SCHUM.) BLY. EX ROWL.) e coroa-de-frade (Melocactus bahiensis BRITTON \& ROSE). Revista Caatinga. 20(1): 28-35, 2007.

11. Andrade CTS, Marques JGW, Zappi DC. Utilização medicinal de cactáceas por sertanejos baianos. Rev. Bras. PI. Med.8(3): 36-42, 2006.

12. Miguel OG, Davet A, Virtuoso S, Dias JFG, Miguel MD, Oliveira AB. Atividade antibacteriana de Cereus jamacaru DC, Cactaceae. Revista Brasileira de Farmacognosia. 16(3): 561-564, 2009.

13. Necchi RMM. Farmacobotânica, atividade anti-inflamatória e parâmetros bioquímicos de nopalea conchenillifera (L.) SALMDICK (cactácea). Santa Maria 14 de Março de 2011.

14. Santos MVF, Lira MA, Junior JCBD, Guim A, Mello ACL, Cunha MV. Potential of Caatinga forage plants in ruminant feeding. R. Bras. Zootec., v.39, p.204-215, 2010 (supl. especial).

15. Necchi RMM, Alves IA, Alves SH, Manfron MP. In vitro antimicrobialactivity, total polyphenols and flavonoids contents of Nopalea cochenillifera (L.) Salm-Dyck (Cactaceae). Research in Pharmacy 2(3) : 01-07, 2012.

16. Messias JB, Caraciolo MCM, Oliveira IM, Montarroyos UR, Bastos IVGA, Guerra MO, Souza IA. Avaliação dos parâmetros hematológicos e bioquímicos de ratas no segundo terço da gestação submetidas à ação do extrato metanólico de Cereus jamacaru DC., Cactaceae. Revista Brasileira de Farmacognosia. 20(4): 478-483, 2010.

17. Brito AF, Figueira ACG, Silva GA. Avaliação da toxicidade de plantas medicinais brasileiras por meio do bioensaio com Artemia salina. Disponível em: < http://ceres.facer.edu.br/anais/index.php/ji/article/view/18 > Acesso em: setembro de 2015. 
18. Trenti DS, Giordani RB, Macedo AJ. Biofilmes bacterianos patogênicos: Aspectos gerais, importância clinica e estratégia de combate. Revista liberato, Novo Hamburgo, v. 24, n. 22, p. 113 à 238, jul./dez. 2013.

19. Costa JCM et al. Increase in biofilm formation by Escherichia coli under conditions that mimic the mastitic mammary gland. Cienc. Rural [online]. 2014, vol.44, n.4, pp. 666-671. ISSN 0103-8478.

20. Silva HTD. Potencial de compostos fenólicos como antimicrobianos e/ou moduladores da resistência em Staphylococcus aureus. 2015.

21. Junior MSB et al. Efeitos da atividade antimicrobiana do extrato bruto etanólico da Piper SOLMSIANUM e Equisetum Arvense. Eletronic Journal of Pharmacy, vol XIII, n. 2, p. 100-1006, 2016.

22. Bussmann RW et al. Toxicity of medicinal plants used in traditional medicine in Northern Peru. Journal of ethnopharmacology, [s.I.], v. 137, p. 121-140, 2011.

23. Bahia EVA, Morais LRV, Silva MP, Lima OBV, Santos SF. Estudos das características físico-químicas do fruto do mandacaru (Cereus jamacaru P.DC.) cultivado no sertão pernambucano. Disponível em: <connepi.ifal.edu.br/ocs/index.php/connepi/ CONNEPI2010/paper/viewFile/1149/34>. Acesso em: outubro de 2014.

24. Brito NM, Nascimento LC, Coelho MSE, Félix, LP. Efeitos de óleos essenciais na germinação de sementes de Cereus jamacaru. Revista Brasileira de Ciências Agrárias. 5(2): 207-211, 2010.

25. Argenta SC, Argenta LC, Giacomelli SR, Cezarotto VS. Plantas medicinais: cultura popular versus ciência. Vivências. Vol.7, N.12: p.51-60, Maio/2011.

26. Koneman EW. Diagnostico Microbiológico: texto e atlas colorido. $5^{\text {a }}$ edição. Rio de Janeiro: Medsi Editora Médica e Científica Ltda, 2001. 458p.

27. Meyer N. Brine shrimp: a convenient general bioassay for active plant constutints. Planta Médica. 45(1): 31, 1982.

28. Briceño DF, Correa A, Valencia C, Torres JÁ, Pacheco R, Montealegre MC, Ospina D, Villega MV. Grupo de resistncia bacteriana nosocomical de colombia. Actualización de laresistencia a antimicrobianos de bacilos Gram negativos aisladosenhospitales de nivel III de Colombia: años 2006, 2007 y 2008.

29. Corrêa IMO, Flores F, Schneiders GH, Pereira LQ, Brito BG, Lovato M. Detecção de fatores de virulência de Escherichia coli e análise de Salmonella spp. em psitacídeos. Pesq. Vet. Bras. 33(2):241-246, fevereiro 2013.

30. Labarca JL. Desde el aporte local al control de laresistencia bacteriana en Chile. RevChillnfect 2011; 28 (1): 12-13.

31. Moura MRAL, Mello MJG, Calábria WB, Germano EM, Maggi RRS, Correia JB. Frequência de Escherichia coli e sua sensibilidade aos antimicrobianos em menores de cinco anos hospitalizados por diarreia aguda. Rev. Bras. Saúde Matern. Infant., Recife, 12 (2): 173-182 abr. / jun., 2012.

32. Nerd A, Dumoutier M, Mizrahi Y. Properties and postharvest behavior of the vegetable cactus Nopaleacochenillifera. Postharcesr Biologyand Technology IO (1997) 135- 143.

33. Oliveira AC, Silva RS. Desafios do cuidar em saúde frente à resistência bacteriana: uma revisão. Revista Eletrônica de Enfermagem. 2008;10(1):189-197.

34. Roque AA, Rocha RM, Loiola MIB. Uso e diversidade de plantas medicinais da Caatinga na comunidade rural de Laginhas, município de Caicó, Rio Grande do Norte (nordeste do Brasil). Rev. Bras. PI. Med., Botucatu, v.12, n.1, p.31-42, 2010. 
35. Silva DS, Andrade MVM, Andrade AP, Carneiros MSS, Oliveira JS. Bromatologic composition of the herbaceous species of the Northeastern Brazil Caatinga. R. Bras. Zootec., v.40, n.4, p.756-764, 2011.

36. Silveira GP, Nome F, Gesser JC, Sá MM. Estratégias utilizadas no combate a resistência bacteriana. Quim. Nova, Vol. 29, No. 4, 844-855, 2006.

37. Weckx L. Antibiotics: from use to abuse. Brazilian Journal of Otorhinolaryngology 78 (2) March/April 2012.

38. Brasil. Farmacopeia brasileira, volume 2. Agência Nacional de Vigilância Sanitária, $5^{a}$ ed. Brasília, 2010. 546p., Iv/il.

39. CETESB. Norma técnica. L5.201. Contagem de bactérias heterotróficas: método de ensaio. 2006. 14 p.

Submetido em: 19/11/2016 Aceito em: 05/07/2017

Publicado em: 30/09/2017 